\section{Pretty proteins}

\section{C.D. Rodger}

Proteins: Structure, Function, and Genetics. Editor-in-chief C. Levinthal. Alan R. Liss. 8/yr. US \$150; elsewhere $\$ 176$.

AT FIRST sight, the very title of this new journal may seem surprising; overwhelmed by the advances in work on nucleic acids, one could be forgiven for thinking that protein research is no longer paramount and can be catered for by the existing journals of biochemistry and molecular biology. However studies of proteins continue to produce exciting information: three-dimensional structure determinations have been speeded up by the use of synchrotron radiation for X-ray diffraction, our ability to manipulate nucleic acids has enabled easier determinations of amino acid sequences, and sitedirected mutagenesis provides methods of manufacturing synthetic polypeptides. There is no shortage of material for a new publication in this area.

Proteins first appeared in September 1986, and was intended to appear monthly. This schedule slipped, however,

\section{PROTEINS}

Structure, Function, and Genetics

apparently because of a lack of highquality contributions. Each issue contains approximately ten papers, sometimes including an initial review article. The format of the contributions follows a good scientific style and includes a useful abstract. The journal appears to cater mainly for full papers and initially no short contributions of the "letter to the editor" type were included, though there has been some editorial comment. Shorter contributions are invited for a "comment" column but this has not yet materialized.

I found it difficult to classify the papers into the subcategories of structure, function and genetics, but a rough analysis of the four issues sent to me for review indicated that the journal was mainly attracting papers dealing with protein structure. This does not mean that this is a crystallographers' journal, however, for there are few of the standard "structure determinations at 2.5 Angstroms resolution" articles to be found elsewhere. There was reference to protein genetics in about a quarter of the contributions. either from the evolutionary standpoint or in terms of mutagenic approaches to produce "designer proteins". Further papers in the latter area especially could help the journal carve out a useful niche for itself.

The standard of production is excellent. The journal is attractively bound in a coloured cover and is printed on glossy paper. The text is large and easy to read, as are the graphs and tables. The paper quality allows for good reproduction of photographic material and colour has been used to very good effect, especially in depicting computer simulations of three-dimensional protein structures.

The editorial board is composed of some 40 distinguished figures from the general area of protein research. Although most are based in the United States, the board does include representatives from eight other countries and approximately one-third of the contributions to the four issues were from

\section{Budding with promise}

\section{Peter A. Meacock}

Yeast. Editor S. G. Oliver Wiley. 4/yr. $U K £ 60$, elsewhere $\$ 110$.

NOWADAYS no self-respecting biologist or biotechnologist who professes an interest in the way cells work can afford to limit his, or her, acquaintance with yeasts to the occasional imbibing of a well-fermented brew. Over the past decade the application of molecular cloning and related genetic techniques to that old stalwart Saccharomyces cerevisiae has triggered a vigorous growth of yeast research activity. Indeed these new technologies, supported by a long history of detailed fermentation and biochemical studies, now make the humble bakers' yeast a supremely versatile organism for investigation of many fundamental problems of eukaryotic cell biology. The upsurge of academic interest has been paralleled in the commercial sector, especially within biotechnology companies, by the realization that yeasts offer enormous potential as production organisms.

Yeast was launched into this ferment of activity in September 1985. It is aimed at a very distinct gap in the scientific literature - up to now, papers on yeast have been scattered throughout 20 or more journals making it difficult for anyone to keep abreast of all developments.

With the declared intention of providing "a forum for yeast researchers", the new journal includes, along with original papers and reviews, items such as news from culture collections, a calendar of meetings worldwide and reports of symposia proceedings. To date the quality of the original contributions has been high, no doubt assured by the eminence of the editorial board. Many aspects of yeast genetics, metabolic biochemistry and cell biology have been covered, although, not surprisingly, the content has been institutions outside the United States.

My overall impression of the papers published so far is that they are of high academic quality. The time between submission and publication seems quite short at present, and this should stimulate the flow of contributions. The breadth of coverage means that the journal should appeal to a reasonably wide audience, and if the quality of the articles is maintained, and the publication schedule adhered to, Proteins should do well.

C.D. Rodger is Biology Course Coordinator in the Department of Sciences, Roehampton Institute of Higher Education, London SW15 5PJ, $U K$.

dominated by studies on $S$. cerevisiae involving molecular biology and genetics. However, other yeasts of importance to man, such as the pathogen Candida albicans and the food spoilage organism Zygosaccharomyces baillii, have not been totally unrepresented.

The review articles are particularly helpful. They provide the reader with a concise introduction to many of the complexities of yeast biology, and they will be welcomed by both established yeast workers and newcomers. Overall, the production standards are extremely high, and the presentation is clear and inviting. This is a journal that can be read and digested comfortably in a favourite armchair.

My only criticism is of the publication frequency, which is quarterly with articles appearing six to nine months after receipt. I fear this may cause many potential contributors to continue to submit their

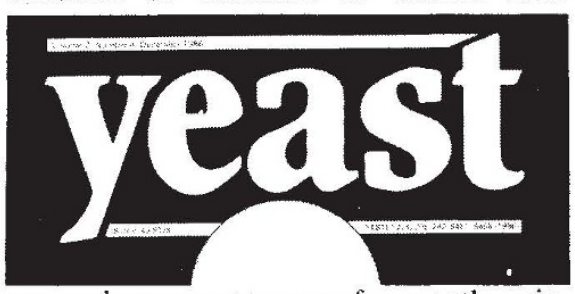

research papers to more frequently printed journals. For this reason, too, papers describing yeast research of major biological significance will probably continue to be attracted to the widely read, highprofile periodicals that can guarantee rapid publication.

Nevertheless if you are either an already committed yeast researcher or merely an onlooker wanting to keep pace with an exciting field, then this journal will be of interest and of service to you. Let us hope that the yeast community really does use it as its forum, by both contributing and subscribing to it. It would be regrettable if this budding journal became arrested at its start.

Peter A. Meacock is Deputy Director and Research Group Leader at the Leicester Biocentre, University of Leicester, University Road, Leicester LEI 7RH, UK. 